\title{
EFFECT OF AGING ON MINERAL CONTENT OF RESIN-DENTIN INTERFACE TREATED WITH TOTAL ETCH ADHESIVES
}

\author{
Yasser Maher El-Bouhi* ${ }^{*}$ Wahdan M. A. El-Kwatehy ${ }^{* *}$ and Nada Ali A. Aleem ${ }^{* * *}$
}

\begin{abstract}
Background/Aim: Slow release of fluoride from adhesives increases the concentration of fluorapatite in the hybrid layer and the underlying dentin and subsequently stabilizes the adhesive joint interface. The present study aimed to evaluate the effect of aging on the mineral content of the bonded resin/dentin interface and to compare between two similar commercial adhesive systems.

Materials and Methods: This in vitro study was carried out on 20 caries-free upper and lower human molar teeth. All the procedures of acid etching, application of adhesives and resin composite buildup were restricted to dentin. Each tooth was prepared to receive Adper Single Bond 2 adhesive system on one half (Group I) and Prime \& Bond NT on the other half (Group II). Sticks from the same tooth half of each adhesive system were mixed and then randomly divided into 3 subgroups according to storage time regimen: immediate, 3 months and 9 months in distilled water. The mineral content at resin-dentin interfaces was analyzed using an environmental scanning electron microscope and energy dispersive analytical $\mathrm{x}$-ray that was expressed as an atom percentage of the total area evaluated. Oneway ANOVA followed by Tukey's pair-wise comparison test were used to determine the significant effect of aging on the mineral content of resin-dentin interface. Comparison between the two adhesives at different time intervals was done using independent student $t$ test, with $\mathrm{p}$ value less than 0.05 considered statistically significant.
\end{abstract}

Results: There was significant difference among different follow up intervals regarding the mineral content of group I $(\mathrm{p}=0.040)$, while group II showed non-significant difference at same intervals $(\mathrm{p}=0.093)$. When the results of the two adhesives were compared to each other, there was no statistically significant difference between them in all of the storage periods except at 9 months ( $\mathrm{p}=0.050)$.

Conclusions: Both adhesives had an influence on the adhesive dentin interface's durability and resistance to degradation. Prime \& Bond NT provided higher mineral content than Adper Single Bond 2 at all storage intervals tested.

KEYWORDS: Total etch adhesives, resin dentine interface, mineral content, energy dispersive analytical x-ray (EDAX).

* Consultant, Alexandria Dental Research Center, Semouha,Alexandria, Egypt.- Assistant Professor of Conservative and Restorative Dentistry Department, College of Dentistry, Umm Al-Qura University, Saudi Arabia;

** Assistant professor of Dental Public Health and Preventive Dentistry Department, Faculty of Dentistry, Mansoura University, Egypt and College of Dentistry, Umm Al-Qura University, Saudi Arabia.

***Assistant Professor, Conservative and Restorative Dentistry Department, College of Dentistry, Umm Al-Qura University, Saudi Arabia. 


\section{INTRODUCTION}

The continuous development of dental adhesives and their ability to preserve tooth structure and to reduce the prevalence of restorations' failure was responsible for a paradigm shift in dentistry. Recently, the minimal invasive dentistry approach has emerged to maximize the preservation of the normal tooth structure. Resin composite firmly adheres to tooth structure and plays an important role to preserve the remaining tooth structure. The development of recurrent caries and loss of interface integrity are the main challenges compromising bonded restorations leading to failure and replacement of the restoration as well as more loss of tooth structure ${ }^{[1]}$.

Fusayama in 1979 reported that, the concept of "total-etch" using phosphoric acid etching of enamel as well as dentin improved the bonding of resin restorations with tooth structure ${ }^{[2]}$. Unfortunately, many studies reported that the bond strength to dentin continued to decrease by time, in an aqueous environment due to the absorption of water that might affect the mechanical properties of the resin matrix material, which in turn, deteriorates the bond performance $^{[3,4]}$.

Many studies have indicated that enamel and dentin can be remineralized after a cariogenic challenge to prevent further demineralization of tooth structure, so that many fluoride-releasing restorative materials have been developed ${ }^{[5,6]}$. Given that, there are several obstacles facing the development of dental adhesives with effective bonding properties to both enamel and dentin, but still being able to produce more durable restorations that withstand marginal leakage and prevent recurrent caries ${ }^{[7]}$.

Studies have indicated that, addition of fluoride to resin composite may improve the bonding properties and adhesion between restoration and tooth structure through promoting remineralization of demineralized tooth hard tissues and leading to the formation of acid resistant fluorapatite crystals ${ }^{[8,9]}$.

The fluoride-releasing adhesives are known to increase the strength of dentin against the acid attacks and exert an anticariogenic activity in the oral environment ${ }^{[10]}$. Slow release of fluoride from the adhesive increases the formation of fluorapatite in the hybrid layer and surrounding dentin. The increased concentration of fluoride in these areas continue even after immersion in water for several weeks ${ }^{[11-13]}$. The released fluoride from adhesives stabilizes the mineral content of the dentin adhesive interface and prevents degradation of dentin. Da Silva et al. found that a fluoridecontaining adhesive system reduced the rate of caries formation and showed a reasonable bonding results when maintained in water for one year [14]. Costa et al. 2014, recorded the fluoride ions released from fluoride-containing adhesive system in demineralization/remineralization solutions and concluded that fluoride was released in a very low concentration into the solutions because the dentin/ composite interface exposed to solution was very small $^{[15]}$.

Dentin's high organic content and continuous humidity make resin composite bonding difficult. Many new materials have recently been developed to improve adhesive properties, but there is still a lack of evidence, as dentists depend on theoretical knowledge gathered from industry representatives, continuing education courses, and dental meetings ${ }^{[16]}$.

The acceptable clinical results obtained from dental adhesives have expanded their usage across different dental disciplines. The concentrations of minerals in the adhesive/dentine interface and their stability with time need further evaluation, so that the current study was performed to assess the effect of aging on the mineral content of the bonded resin/ dentin interface and to compare between two similar commercial adhesive systems. 


\section{MATERIALS AND METHODS}

\section{Study design}

Twenty caries-free human upper and lower molar teeth were used in this laboratory experiment. The teeth were carefully cleaned and washed, and a magnification lens of $\times 7$ was used to inspect them for any cracks or developmental defects. They were then preserved in distilled water containing $0.02 \%$ sodium azide at $4^{\circ} \mathrm{C}$.

\section{Materials}

The materials used in the present study were two conventional etch-and-rinse two-step adhesives; Adper Single Bond 2 and a Prime \& Bond NT. A resin composite restorative material (Filtek Supreme XT). The composition of these materials was presented in the following table.

\section{Sample preparation}

All the procedures of acid etching, application of adhesives and resin composite buildup were restricted to dentin. Each tooth was prepared to receive Adper Single Bond 2 adhesive system (fluoride-free adhesive) on one half (Group I) and Prime \& Bond NT (fluoride containing adhesive) on the other half (Group II).

3-4 mm below the cemento-enamel junction, the roots were cut and removed. After exposure at the furcation area, the contents of the pulp chamber were carefully removed. Each tooth was then divided into two equal dentin halves by a $1 \mathrm{~mm}$ enamel rim that extended from the mid-point of the cementoenamel junction on the proximal surface to the mid-point of the cementoenamel junction on the opposite proximal surface, dividing the occlusal surface into two equal halves (buccal and lingual).

The proximal surfaces were ground flat parallel to the tooth's long axis, while the occlusal surfaces were ground flat to reveal a flat dentin surface parallel to the occlusal surface and perpendicular to the tooth's long axis. Repeated measurements with a pincer Iwanson thickness gauge (Renfert $\mathrm{GmbH}$, Hilzingen, Germany) during grinding were used to adjust the dentin thickness to $3 \mathrm{~mm}^{[17]}$.

TABLE (1): The specification and composition of Adhesives and resin materials

\begin{tabular}{|l|l|l|l|}
\hline Material & Specifications & Composition & Manufacturer \\
\hline $\begin{array}{l}\text { Adper Single } \\
\text { Bond }\end{array}$ & $\begin{array}{l}\text { Two-step } \\
\text { etch-and-rinse } \\
\text { adhesive } \\
\text { system }\end{array}$ & $\begin{array}{l}\text { Etchant: } 37 \% \mathrm{H}_{3} \mathrm{PO}_{4} \\
\text { Adhesive: Bisphenol A diglycidylmethacrylate (Bis-GMA), } \\
\text { 2-Hydroxyethyl methacrylate (HEMA), water, dimethacrylates, } \\
\text { ethanol methacrylate functional copolymer of polyacrylic and } \\
\text { polyitaconic acids, photoinitiators, nanofiller 10\% by weight 5 nm } \\
\text { spherical silica particles }\end{array}$ & $\begin{array}{l}\text { PM ESPE, St. } \\
\text { Uaul MN, } \\
\text { USA }\end{array}$ \\
\hline $\begin{array}{l}\text { Prime \& Bond } \\
\text { NT }\end{array}$ & $\begin{array}{l}\text { Two-step } \\
\text { etch-and-rinse } \\
\text { adhesive } \\
\text { system }\end{array}$ & $\begin{array}{l}\text { Etchant: 36\% } \mathrm{H}_{3} \mathrm{PO}_{4} \\
\text { Adhesive: dipentaerythritol pentaacrylate monophosphate (PENTA), } \\
\text { Triethyleneglycoldimethacrylate (TEGDMA), Bis-GMA, cetylamine } \\
\text { hydrofluoride, acetone, nanofiller (amorphous silicon dioxide 8 nm), } \\
\text { resin R5-62-1, T-resin, D-resin, camphoroquinone (CQ) }\end{array}$ & $\begin{array}{l}\text { Konstanz, } \\
\text { Germany }\end{array}$ \\
\hline $\begin{array}{l}\text { Filtek Supreme } \\
\text { XT Universal } \\
\text { Restorative } \\
\text { Material }\end{array}$ & $\begin{array}{l}\text { Visible light } \\
\text { cured } \\
\text { nanofilled } \\
\text { resin } \\
\text { composite }\end{array}$ & $\begin{array}{l}\text { Organic part: BIS-GMA, urethane dimethacrylate (UDMA), } \\
\text { bisphenol A polyethylene glycol diether dimethacrylate (BISEMA) } \\
\text { and TEGDMA. } \\
\text { Inorganic part: Zirconia / silica cluster with an average cluster } \\
\text { size 0.6-1.4 micron with primary particle size of 5-20nm. The } \\
\text { nonagglomerated/nonaggregated silica filler is 59.5\% by volume }\end{array}$ & $\begin{array}{l}\text { PM ESPE, St. } \\
\text { Paul MN, } \\
\text { USA }\end{array}$ \\
\hline
\end{tabular}




\section{Storage conditions}

An incubating container was constructed in a trial to simulate the intraoral condition during the experiment testing periods; it prevented the teeth and the packed resin composite from dehydration as the specimens were immersed in a water bath (before and after resin composite build up) and maintained at fixed temperature which was $37^{\circ} \mathrm{C} \pm$ $0.1^{\circ} \mathrm{C}$

\section{Application of the adhesive system}

The bonding and restoration procedures of the operated teeth were done in a dry condition to simulate the clinical situation where the moisture control and isolation should be perfectly performed. To assure complete hydration (infiltration) of dentinal tissue, the specimens were perfused 24 hours prior to the bonding and resin composite buildup procedures ${ }^{[18]}$. All teeth were connected to a pipeline perfusion system containing distilled water, which level was kept constant at a level higher than the teeth by $15 \mathrm{~cm}$ to simulate the physiologic natural intra-pulpal pressure of $15 \mathrm{~cm} \mathrm{H}_{2} \mathrm{O}$, or 1.5 $\mathrm{kPa}$ or $11.1 \mathrm{~mm} \mathrm{Hg}{ }^{[19,20]}$.

The intra-pulpal pressure of the operated teeth was maintained, i.e. having a constant pressure, temperature, and continuous hydration. This was achieved by making several rows of teeth from which any row can be moved out and then back in the box freely.

Phosphoric acid etchant was applied to dentin surface for 15 seconds then rinsed. Excess water was removed with sponge pellet avoiding excessive dryness (wet bonding). Two layers of adhesive were applied and gently air-dried for $5 \mathrm{sec}$ at $5 \mathrm{~cm}$ distance, which allowed the solvent to evaporate. Each applied adhesive layer was light cured for $10 \mathrm{sec}$.

Three $2 \mathrm{~mm}$ increments of a hybrid nano-filled resin composite were used to create a $6 \mathrm{~mm}$ thick block. Each increment was cured for 40 seconds before being immersed in distilled water for 24 hours at $37^{\circ} \mathrm{C}$. The blocks were then sectioned with a diamond blade and a water-cooling system to obtain sticks with a cross-sectional area of $1 \mathrm{~mm}^{2}$. The sticks from the same tooth half were mixed and then randomly divided into three subgroups according to storage time regimen: immediate, 3 months, and 9 months in distilled water.

Feitosa et al. (2014) identified a simple method for putting the samples under the effect of pulpal pressure by placing them under water bath at depth equals that of the desired height, $15 \mathrm{~cm}^{[21]}$.

\section{Mineral content analysis by ESEM/EDAX:}

An environmental scanning electron microscope (FEI Quanta 200 ESEM, France) was used to analyze the mineral content at resin-dentin interfaces. It was operated in backscattered electron mode at 1600 magnification and EDAX (energy dispersive analytical $\mathrm{x}$-ray). The mineral content of the dentinadhesive interface, adhesive layer, hybrid layer, and resin tags in each specimen was measured directly on the ESEM microscope monitor in four regions for each beam in an area of $(170 \mu \mathrm{m} \times 170 \mu \mathrm{m})$. The mean of the four regions was calculated and four beams were taken from each tooth. The different minerals were presented as atom percentage of the total area evaluated (Figure 1).

\section{Statistical analysis:}

The results were collected and statistically analyzed for significance between the groups using SPSS for Windows (version 22, IBM, Corp., Chicago, IL, USA). One-way ANOVA and Tukey's pair-wise tests were used to determine significant effect of aging on the mineral content of resindentin interface at different follow up intervals. Comparison between the two adhesives was done using independent student $\mathrm{t}$ test. The $\mathrm{p}$ value $\leq 0.05$ was considered statistically significant. 


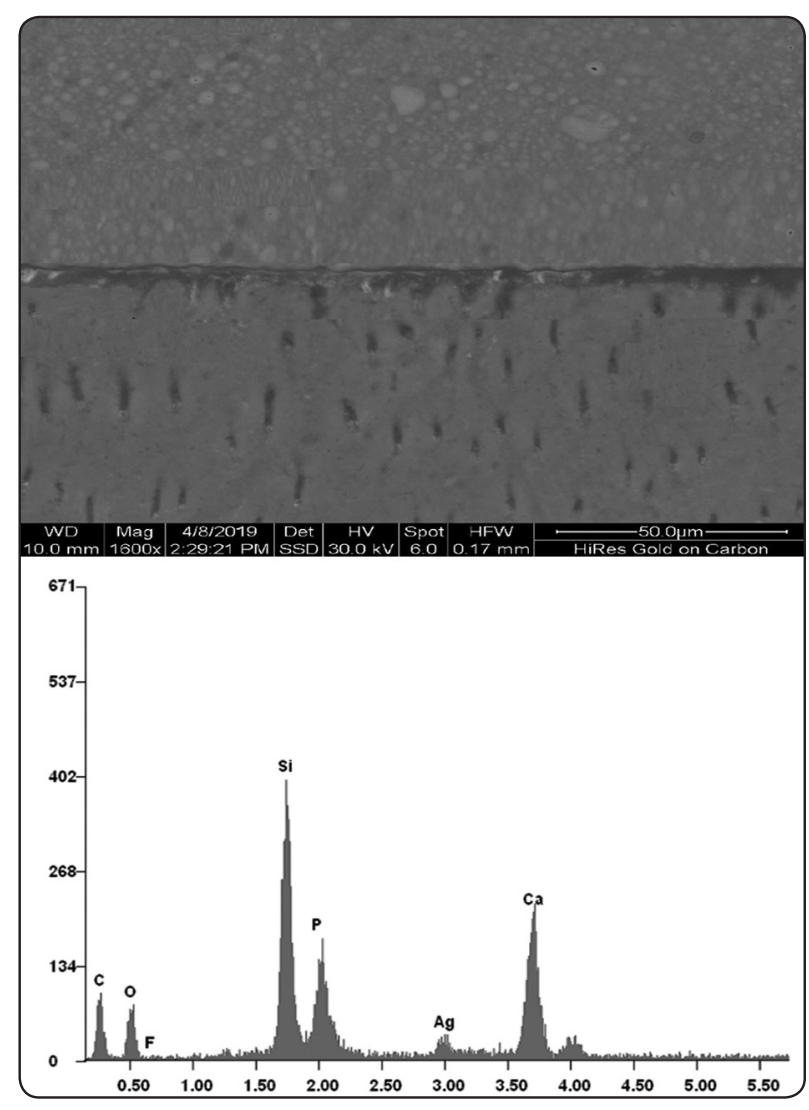

Fig. (1) Shows the EDAX pattern of fluoride, calcium and phosphorus elements at resin/dentin interface

\section{RESULTS}

For each adhesive, there were non-significant differences among different follow up intervals, regarding fluoride and calcium, while phosphorus showed a significant difference between storage intervals; for both adhesives ( $\mathrm{p}=0.044$ for Group I and $\mathrm{p}=0.028$ for Group II).

When comparing the two adhesives, the differences between the two groups were not significant regarding fluoride and calcium; at all follow up intervals. While, with phosphorus; the difference was non-significant at the immediate analysis but was statistically significant at 3- and 9-months intervals ( $\mathrm{p}=0.025$ and $\mathrm{p}=0.047$ respectively).
Also, comparison of the two adhesives revealed that regarding their collective total mineral content, there were significant differences among different follow up intervals for Group I ( $\mathrm{p}=0.040)$, while there was non-significant difference in Group II $(\mathrm{p}=0.093)$. On the other hand, there was no differences between the two adhesives except at 9 months scores $(\mathrm{p}=0.050)$ (Table 2).

TABLE (2): The effect of aging of Adper single bond and Prime \& Bond NT on mineral content of resin dentin interface.

\begin{tabular}{|c|c|c|c|c|}
\hline & Variables & Group I & Group II & $\mathrm{p} 1$ \\
\hline & Immediate & $0.398 \pm 0.125$ & $0.401 \pm 0.174$ & 0.945 \\
\hline \& & 3 months & $0.341 \pm 0.261$ & $0.402 \pm 0.248$ & 0.501 \\
\hline$\frac{\vec{I}}{I I}$ & 9 months & $0.300 \pm 0.192$ & $0.370 \pm 0.198$ & 0.317 \\
\hline & $\mathrm{P}$ & 0.392 & 0.886 & \\
\hline & Immediate & $3.348 \pm 0.561$ & $3.410 \pm 0.618$ & 0.769 \\
\hline$\Xi$ & 3 months & $3.349 \pm 0.834$ & $3.264 \pm 0.307$ & 0.705 \\
\hline Uี & 9 months & $2.894 \pm 0.433$ & $3.121 \pm 0.430$ & 0.147 \\
\hline & $\mathrm{P}$ & 0.074 & 0.231 & \\
\hline & Immediate & $3.121 \pm 0.306^{\mathrm{A}}$ & $3.363 \pm 0.382^{\mathrm{C}}$ & 0.056 \\
\hline है & 3 months & $2.883 \pm 0.520$ & $3.263 \pm 0.376$ & $0.025^{*}$ \\
\hline o & 9 months & $2.741 \pm 0.407^{\mathrm{A}}$ & $3.014 \pm 0.334^{C}$ & $0.047^{*}$ \\
\hline & $\mathrm{P}$ & $0.044^{*}$ & $0.028^{*}$ & \\
\hline & Immediate & $6.866 \pm 0.818^{\mathrm{B}}$ & $7.174 \pm 1.037$ & 0.358 \\
\hline$\pi$ & 3 months & $6.573 \pm 1.373$ & $6.928 \pm 0.682$ & 0.361 \\
\hline & 9 months & $5.935 \pm 0.770^{\mathrm{B}}$ & $6.501 \pm 0.807$ & $0.050^{*}$ \\
\hline & $\mathrm{P}$ & $0.040^{*}$ & 0.093 & \\
\hline
\end{tabular}

Group I = Adper single bond 2, Group II = Prime \& Bond NT, $S D=$ Standard Deviation, $p=p$ value calculated by One-Way ANOVA test, $p 1=p$ value calculated by independent student $t$ test, ${ }^{A, B, C}=$ similar liters mean significant differences between the corresponding follow up in the same column, $=$ significant $p$ value. 


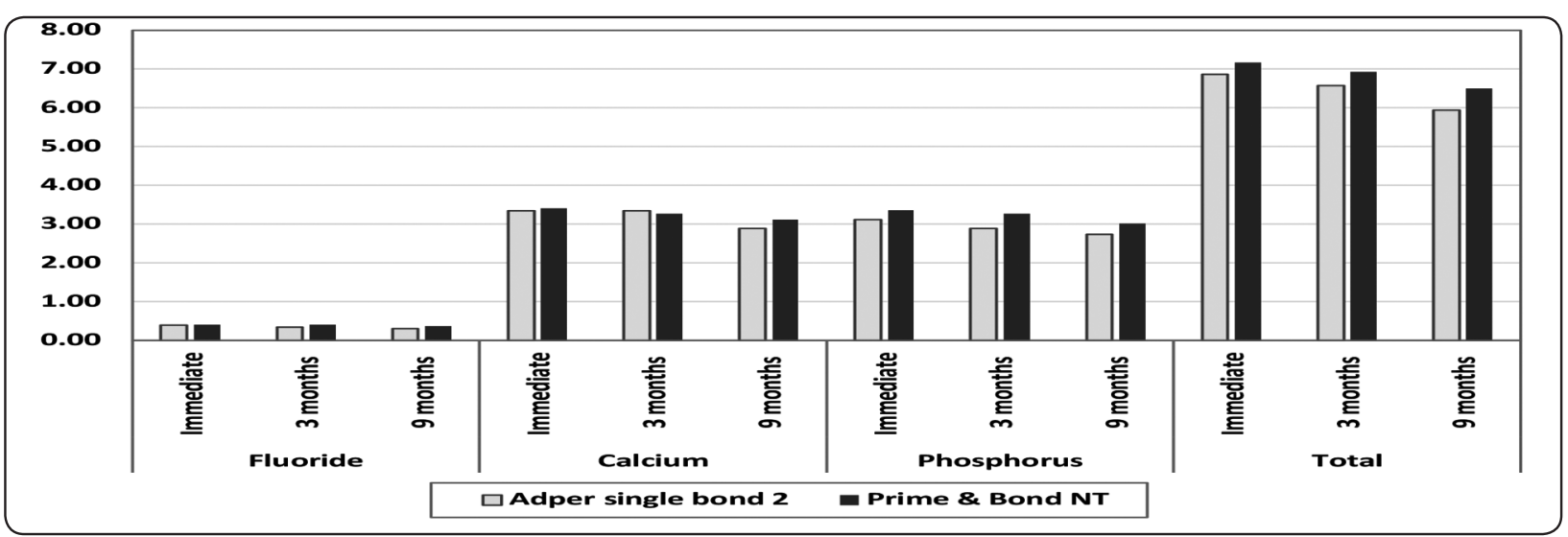

Fig. (2): The effect of aging on mineral content of adhesive dentin interface treated with Adper Single Bond 2 and Prime \& Bond NT adhesives.

\section{DISCUSSION}

Several studies have mentioned incorporating fluoride in some resin composite restorative materials and adhesive systems for the purpose of preventing recurrent caries ${ }^{[22,23]}$. Other studies showed the ability of adhesive systems to prevent development of secondary carious lesions, inhibit dentin degradation, and thus increase the adhesive interface's stability. [24-26]. However, previous studies have not clarified the cause of that finding, while the results of the present study suggested that fluoride-releasing adhesives might preserve the mineral content of tooth structure; due to the formation of fluoro-apatite crystals at the adhesive dentin interface area. So that, EDAX was used to determine the mineral content in the resin dentin interface at different follow-up intervals and to compare two total-etch adhesives.

In the present study, each adhesive was applied on one half of the same tooth to overcome the possible variation of the mineral content between different teeth. Also, the perfusion system was used during all experiment stages including the adhesive application, resin composite packing and storage of specimens to simulate the intra-pulpal pressure and oral environmental conditions. The intra-pulpal pressure is very important to maintain wettability of collagen fibers of the etched dentinal tubules and preserve their originality to facilitate penetration of adhesive monomers [27]. Previous studies have shown that as compared to dry bonding, wet bonding produces deeper penetration of the resin monomer into the etched layer of dentin, resulting in higher bond strength. ${ }^{[28,29]}$.

The etch-and-rinse technique used in the present study removed the smear layer, the smear plugs, and the inter-tubular mineral content of dentin ${ }^{[30]}$, thus overcame the effect of smear layer on mineral content of resin dentin interface area during the EDAX assessment.

The present results revealed that Prime \& Bond NT had a higher mineral content at the dentine interface than Adper Single Bond 2, despite the fact that the differences were not significant at the immediate and 3-month intervals (Table 2 and Figure 2). This may be due to the formation of fluoro-apatite crystals in the presence of fluoridereleasing adhesive (Prime \& Bond NT), which maintained higher level of calcium, phosphorus and fluoride. These findings confirmed previous findings that suggested mineral content degradation at the resin/dentin interface after long-term storage in water ${ }^{[31,32]}$. The concentration of minerals at the interface area may be directly related to the resistance of both the adhesive and collagen fibers against hydrolytic degradation. So that, the increased mineral concentration could result in better bond performance and increased bond strength. This 
assumption explains many previous studies that reported the presence of correlation between age degradation and deterioration of bond strength ${ }^{[25,33]}$.

Both tested adhesives showed non-significant reductions in fluoride and calcium, but significant reductions in phosphorus, after nine months of water storage. Although the total mineral content of Prime \& Bond NT group was higher in all test periods, both adhesives performed similarly in terms of the aging effect of the adhesive on the mineral content of the adhesive dentin interface area (Figure 2) The present results agreed with that reported by Costa et al. and Reis et al. ${ }^{[15,34]}$

The released fluoride ions penetrate and diffuse through the dentin walls, increasing mineralization, inhibiting dentinal demineralization, and improving age resistance, which is expected to minimize the risk of recurrent caries ${ }^{[4,12,35,36]}$.

According to the current findings, both Prime $\&$ Bond NT and Adper Single Bond 2 adhesives affected the adhesive dentin interface's stability and degradation resistance. At all test intervals, however, Prime \& Bond NT produced higher mineral content than Adper Single Bond 2.

\section{CONCLUSION}

According to the results of the current study it could be concluded that:

1- Application of fluoride-containing adhesives could positively influence the concentration of minerals' content at the resin/dentin interface area.

2-Since both tested adhesives improved the minerals' concentration by time, they are expected to increase the stability and degradation resistance of the adhesive joint.

\section{LIMITATIONS OF THE STUDY}

The present study was performed in vitro under controlled simulated conditions to imitate the clinical intraoral conditions for a time period of 9 months.

\section{RECOMMENDATIONS}

1- Under the limitations of the present study, the application of fluoride containing adhesives is highly recommended when using resin composite to enhance the performance of the adhesives and fight against the bond degradation.

2- Further in vivo studies are required to confirm our findings and to be done for longer clinical follow up periods.

\section{REFERENCES}

1. Perdigão J. New developments in dental adhesion. Dent Clin North Am 2007;51(2):333-57.

2. Fusayama T, Nakamura M, Kurosaki N, Iwaku M. Nonpressure adhesion of anew adhesive restorative resin. $\mathrm{J}$ Dent Res 1979;58(4):1364-70.

3. Cueto EI, Buonocore MG. Sealing of pits and fissures with an adhesive resin: its use in caries prevention. J Am Dent Assoc 1967;75(1):121-8.

4. Van Meerbeek B, De Munck J, Yoshida Y, Inoue S, Vargas M, Vijay P, et al. Buonocore memorial lecture. Adhesion to enamel and dentin: Current status and future challenges. Oper Dent 2003;28(3):215-35.

5. Pinto CF, Paes-Leme AF, Ambrosano GM, Giannini M. In vitro secondary caries inhibition by adhesive systems in enamel around composite restorations. Oper Dent 2010;35:345-52

6. Ayres APA, Tabchoury CPM, Berger SB, Yamautid M, Ambrosano GMB, Giannini M. Effect of fluoridecontaining restorative materials on dentin adhesion and demineralization of hard tissues adjacent to restorations. $\mathbf{J}$ Adhes Dent 2015;17:337-45.

7. Jorge Perdigão; Current perspectives on dental adhesion: (1) Dentin adhesion - not there yet. Japanese Dental Science Review 2020;56: 190-207.

8. Van Meerbeek B, yhara K, Yoshida Y, Mine A, De Munck J, Van Landuyt K. State of the art of self-etch adhesives. Dent Mater 2011;27(1):17-28

9. Szesz A, Parreiras S, Reis A, Loguercio A. Selective enamel etching in cervical lesions for self-etch adhesives: A systematic review and meta-analysis. J Dent 2016; 53:1-11.

10. Itota $\mathrm{T}, \mathrm{Nakabo} \mathrm{S}$, Iwai $\mathrm{Y}$, Konishi N, Nagamine M, Torii Y. Inhibition of artificial secondary caries by fluoridereleasing adhesives on root dentin. J Oral Rehabil 2002; 29:523-7. 
11. Nakajima M, Okuda M, Ogata M, Pereira PNR Tagami J, Pashley DH. The durability of a fluoride-releasing resin adhesive system to dentin. Oper Dent 2003; 28:186-92.

12. Ferracane JL, Mitchem JC, Adey JD. Fluoride penetration into the hybrid layer from a dentin adhesive. Am J Dent 1998;11:23-8.

13. Han L, Edward C, Okamoto A, Iwaku M. A comparative study of fluoride-releasing resin materials. Dent Mater J 2002;21:9-19.

14. da Silva BM, França FM, Flório FM, Basting RT. In situ anticariogenic effect of adhesive systems containing fluoride and MDPB. Am J Dent 2010; 23: 75-80.

15. Costa AR, Correr-Sobrinho L, Ambrosano GMB, Sinhoreti MAC, Borges GA, Platt JA, et al. Dentin bond strength of a fluoride-releasing adhesive system submitted to $\mathrm{pH}$-cycling. Braz Dent J 2014;25:472-8.

16. Perdigão J. Fourteen years later! J Adhes Dent 2016; 18(4):279-80.

17. Hiraishi N., Yiu Y., King N., Tay R.; Effect of 2\% chlorhexidine on dentin micro-tensile bond strengths and nano leakage of luting cements. J Dent 2009;37:440-8.

18. Sengun A., Ozer F., Unlu N., Ozturk B.; Shear bond strengths of tooth fragments reattached or restored. J Oral Rehabil 2003 $30 ; 82-6$.

19. Hosaka K, Nakajima M, Monticelli F, Carrilho M, Yamauti $\mathrm{M}$, Aksornmuang $\mathrm{J}$, et al. Influence of hydrostatic pulpal pressure on the microtensile bond strength of all-in-one self-etching adhesives. J Adhes Dent 2007; 9(5):437-42.

20. Cardoso MV, Moretto SG, Carvalho RC, and Russo EM. Influence of intra-pulpal pressure simulation on the bond strength of adhesive systems to dentin. Braz Oral Res 2008; 22(2):170-5.

21. Feitosa VP, Gotti VB, Grohmann CV, Abuna G, Correr-Sobrinho L, et al. Two methods to simulate intrapulpal pressure: effects upon bonding performance of self-etch adhesives. Int Endod J 2014; 47(9):819-26.

22. Shinohara MS, Yamauti M, Inoue G, Nikaido T, Tagami J, Giannini M, et al.. Evaluation of antibacterial and fluoride-releasing adhesive system on dentin-micro-tensile bond strength and acid-base challenge. Dent Mater J 2006;25:545-52.

23. Guedes A., Moda M., Suzuki T., Godas A., Sundfeld R., et al., Effect of Fluoride-Releasing Adhesive Systems on the Mechanical Properties of Eroded Dentin; Brazilian Dent J 2016; 27(2): 153-9
24. Imazato S, Kinomoto Y, Tarumi H, Ebisu S, Tay FR. Antibacterial activity and bonding characteristics of an adhesive resin containing antibacterial monomer MDPB. Dent Mater 2003;19:313-19.

25. Donmez N, Belli S, Pashley DH, Tay FR. Ultrastructural correlates of in vivo/in vitro bond degradation in self-etch adhesives. J Dent Res 2005;84:355-9.

26. Nikaido T, Ichikawa C, Li N, Takagaki T, Sadr A, Yoshida Y, et al.. Effect of functional monomers in all-in-one adhesive systems of formation of enamel/dentin acid-base resistant zone. Dent Mater J 2011;30:576-82.

27. Tay FR, Gwinnett AJ, Wei SH. The overwet phenomenon: an optical, micromorphological study of surface moisture in the acid-conditioned, resin-dentin interface. Am J Dent 1996; 9:43-8.

28. Nakajima M, Ogata M, Okuda M, Tagami J, Sano H, Pashley DH. Bonding to caries-affected dentin using self-etching primers. Am J Dent 1999; 12:309-14.

29. Yoshiyama M, Urayama A, Kimochi T, Matsuo T, Pashley DH. Comparison of conventional vs self-etching adhesive bonds to caries-affected dentin. Oper Dent 2000; 25:163-9

30. Masarwa N, Mohamed A, Abou-Rabii I, Abu Zaghlan R, Steier L. Longevity of Self-etch Dentin Bonding Adhesives Compared to Etch-and-rinse Dentin Bonding Adhesives: A Systematic Review. J Evid Based Dent Pract. 2016;16(2):96-106.

31. Armstrong SR, Vargas MA, Fang Q, Laffoon JE. Microtensile bond strength of a total-etch 3-step, total-etch 2-step, self-etch 2-step, and a self-etch 1-step dentin bonding system through 15-month water storage. J Adhes Dent 2003;5:47-56.

32. de Munck J, Van Meerbeek B, Yoshida Y, Inoue S, Vargas M, Suzuki K, et al.. Four-year water degradation of total-etch adhesives bonded to dentin. J Dent Res 2003;82:136-40.

33. Burrow MF, Satoh M, Tagami J. Dentin bond durability after three years using a dentin bonding agent with and without priming. Dent Mater 1996;12:302-7.

34. Reis AF, Carrilho MRO, Ghaname E, Pereira PNR, Giannini M, Nikaido T, et al.. Effects of water-storage on the physical and ultra-morphological features of adhesives and primer/adhesive mixtures. Dent Mater J 2010;29:697-705.

35. Domiciano SJ, Colucci V, Serra MC. Effect of two restorative materials on root dentine erosion. J Biomed Mater Res B Appl Biomater 2010;93:304-8.

36. Kirsten GA, Takahashi MK, Rached RN, Giannini M, Souza EM. Microhardness of dentin underneath fluoride-releasing adhesive systems subjected to cariogenic challenge and fluoride therapy. J Dent 2010;38:460-8. 